Hughes, G. B., Giegengack, R. and Kritikos, H. N. (1999), Spectral indications of unexpected contributors to atmospheric $\mathrm{CO}_{2}$ variability?. Int. J. Climatol., 19: 813-819. doi: 10.1002/(SICI)1097-0088(19990630)19:8<813::AID-JOC387>3.0.CO;2-\#

\title{
SPECTRAL INDICATIONS OF UNEXPECTED CONTRIBUTORS TO
}

\section{ATMOSPHERIC $\mathrm{CO}_{2}$ VARIABILITY?}

GARY B. HUGHES ${ }^{\mathrm{a}, *}$, ROBERT GIEGENGACK ${ }^{\mathrm{a}}$ and HARALAMBOS N. KRITIKOS

a Department of Earth and Environmental Science, University of Pennsylvania, Philadelphia, PA 19104, USA

b Department of Electrical Engineering, University of Pennsylvania, Philadelphia, PA 19104, USA

\section{ABSTRACT}

The frequency spectrum of Northern Hemisphere atmospheric $\mathrm{CO}_{2}$ concentration shows strong periodicities at $6.2,1.0$ and 0.5 years. The 6.2 year cyclicity has been attributed to non-linear interactions between the annual cycle and the atmospheric pole tide. The yearly signal is linked to terrestrial photosynthesis; phase analysis shows that annual CO2 minima occur at a lag of approximately 85 days from insolation maxima. Variations in the nominal yearly period occur during times of anomalous anthropogenic $\mathrm{CO}_{2}$ production. Periodicity at 6 months represents a deviation of the yearly signal from an annual sinusoid. If the yearly signal is largely sinusoidal, a plausible source of the 6 month periodicity could be cyclic phytoplankton productivity driven by natural insolation modes. Together, the three largest spectral peaks account for over $99 \%$ of the variation in detrended CO2 data. 


\section{INTRODUCTION}

Charles D. Keeling began making direct measurements of the concentration of $\mathrm{CO} 2$ in the atmosphere in 1958 on the island of Mauna Loa. Since that time, a larger network of monitoring stations has been established over a wide range of latitudes in both the Northern and Southern hemispheres. Daily measurements from these stations provide a high-resolution time series of atmospheric CO2 concentration. A time series plot of Northern Hemisphere records (Figure 1) shows annual oscillations superimposed over a general upward trend. Some interannual and inter-decadal variability is also evident.

Frequency spectrum analysis of the time series data indicates several important features of $\mathrm{CO} 2$ variability that are not apparent in the time domain data. The power spectrum shows significant peaks at periods of 6.2, 1.0 and 0.5 years. The 1-year peak is accordant with the hypothesis that atmospheric $\mathrm{CO}_{2}$ responds to annual fluctuations in the rate of terrestrial photosynthesis (Sarmiento, 1993). Phase analysis shows the expected relationship: atmospheric CO2 minima coinciding with maxima of Northern Hemisphere photosynthesis, with a small hysteresis. The source of the 6.2-year peak has been attributed to non-linear interactions between the annual signal and the atmospheric pole tide (Hameed et al., 1995). The 6-month peak, present in the spectra of most climate variables, represents a deviation of the annual signal from an annual sinusoid. If annual forcing of the $\mathrm{CO}_{2}$ signal is predominantly sinusoidal, then the source of 6 month periodicity may be distinct. Phase analysis indicates a possible link to cyclic phytoplankton primary productivity, conceivably driven by an insolation mode of the same frequency. Together, the three main peaks account for over $99 \%$ of the variation in the detrended CO2 data, suggesting that the complexity of subannual, annual and inter-annual atmospheric CO2 variability is not great. 
Data in Figure 1 represent daily average CO2 concentrations during the period 1 January 1968-31 December 1993, based on data from 20 Northern Hemisphere stations (Conway and Tans, 1998). This is the longest contiguous period of daily records available from that source. Records from these stations were averaged on a day-to-day basis, and these daily averages were used as representative values for the Northern Hemisphere atmospheric CO2 concentration. To investigate the frequency composition of the $\mathrm{CO} 2$ signal, the authors removed the trend in the raw data by linear regression over the period 1968-1993. A flexible cubic smoothing spline (with $\mathrm{A}=0.01$ ) was fitted to the linear residual, and evaluated at 16384 equally spaced points over the domain, providing time resolution of 0.58 days. The Nyquist critical frequency is $f_{\mathrm{c}}: 183$ cycles/year, based on the daily averages.

A discrete Fourier transform (DFT) periodogram of the equally spaced data was calculated. The DFT uses sinusoids (and the constant function 1) as a basis for determining the frequency content of a time series signal. The basis sinusoids are limited to integer-multiple frequencies of a sinusoid that completes exactly one cycle over the time span of the data (wavenumber 1), in this case 26.0 years. That is, subsequent wavenumbers have frequencies that are integer multiples of 0.038 cycles/year (one cycle per 26 years). Wavenumber 26 is thus a sinusoid with a period of 1.0 year. The plot in Figure 2(a) shows spectral power at the first 65 wavenumbers, corresponding to periods between 26.0 years and 4.9 months.

If the time span of the data is changed, the DFT basis frequencies are altered accordingly. In particular, if the time span is not an integer multiple of 1 year, the basis frequencies will not include a wavenumber with a period of exactly 1 year. This feature of the DFT can be exploited to investigate spectral power at different sets of basis frequencies. Alternatively, this approach can be used to target a particular discrete frequency by choosing an 
appropriate time span. This is illustrated in Figure 2(b), which shows the DFT spectrum of the data from 1 July 1968 to 31 December 1993 (again, evaluated with the spline at 16384 equally spaced points over the domain). This spectrum shows an increase in power around the pole tide period of 435 days ( -1.19 years, wavenumbers 22 and 23), which was underestimated by the basis frequencies of the first data set.

The spectrum of CO2 was also computed using the maximum entropy method (MEM) with the same evenly spaced data (Figure 2(c)). This method allows estimation of spectral power at arbitrary frequencies within the Nyquist interval $\left[-f_{c}, f_{c}\right]$, and can more accurately represent a power spectrum containing narrow peaks. Since the method does not rely on a fixed set of basis functions, altering the time span of the data set does not significantly change the MEM spectrum. The Lomb normalized periodogram was also computed, from 16384 randomly spaced data points over the same domain (evaluated with the spline). This method provides a numerically efficient means of estimating the statistical significance of the peaks (Figure 2(d)). A comprehensive discussion of the numerical techniques used to compute these spectra can be found in Press et al. (1992). [Figure 1] [Figure 2] [Figure 3]

The frequency spectrum shows significant peaks at periods of 6.2, 1.0 and 0.5 years. The yearly oscillation has been attributed to variations in rates of terrestrial photosynthesis (Sarmiento, 1993). Maximum depletion of atmospheric CO2 occurs during June-July, when terrestrial photosynthesis in the Northern Hemisphere removes CO2 from the atmosphere more rapidly than it is added from other sources. This connection is supported by phase analysis, which can isolate contributions from individual peaks in the spectrum. The isolated contributions are produced by inverse DFT, after filtering out all wavenumbers except those of interest. The filter/inversion process preserves both phase and amplitude information. An 
isolated 12 month cycle was computed by inverse DFT of wavenumber 26, for data covering 1 January 1968-31 December 1993. The isolated signal (Figure 3) shows annual local minima at Julian day 256 (12-13 September). This result suggests a 1-2 month hysteresis in the response of atmospheric $\mathrm{CO}_{2}$ concentration to seasonal fluctuations in terrestrial photosynthesis. The annual $\mathrm{CO}_{2}$ minima occur at a lag of 85 days from the Northern Hemisphere insolation maxima on 20/21 June.

Variability in atmospheric CO2 that gives rise to the spectral peak at a period of 6.2 years has been attributed to non-linear interactions between the annual cycle and the atmospheric pole tide (Hameed et al., 1995). A regular variation in the Earth's axis of rotation with respect to the mean pole location, termed the Chandler Wobble, has a nominal period of 435 days (1.19 years, -0.84 cycles/year), and an amplitude that ranges from $0.002 "$ to $0.300 "$. Tidal measurements also show variability in sea level at the same period (the oceanic pole tide). Hameed et al. (1995) describe the atmospheric pole tide (APT) as the analogous cycle in air pressure, and present results which indicate that the Chandler Wobble’s excitation may originate in the atmosphere. The spectrum of $\mathrm{CO}_{2}$ shows significant power at the APT period (Figure 2(b)-(d)), possibly resulting from modulation of the insolation cycle. The difference between the annual frequency of 1.00 cycles/year and the APT frequency of -0.84 cycles/year is -0.16 cycles/year ( -6.24 year period). The discrete oscillatory mode in the $\mathrm{CO} 2$ spectrum at 6.2 years is excited by non-linear interaction between variability at the two shorter periods, and is not due to external forcing (a thorough discussion can be found in the reference). The data set spans only four cycles of the APT yearly difference frequency. In this range, the DFT basis frequencies are widely spaced, so the power observed in the DFT spectrum (Figure 2(a) and (b)) occurs at wavenumbers 4 (6.5-year period) and 5 (5.2-year 
period). Since the interaction is non-linear, a peak at the frequency sum (1.84 cycles/year, 0.54 years) should also be present. This peak is seen in the MEM spectrum (Figure 2(c)).

The 6-month peak in the $\mathrm{CO}_{2}$ spectrum is the first harmonic of the 1-year peak, and represents a deviation of the annual signal from an annual sinusoid (Figure 3). It is possible (even likely) that the forcing mechanism of annual CO2 variability is non-sinusoidal in nature. Since the annual cycle is influenced by terrestrial photosynthesis, the yearly cycle of insolation is an important factor. At the equator, the cycle of insolation contains two maxima and two minima every year (i.e. it has a 6.0 month periodicity), but this cycle is nonsinusoidal. Between the Tropic of Cancer and the Arctic Circle, average daily insolation follows a sinusoid with a 1.0 year period. At all latitudes, the spectrum of insolation contains significant power in the harmonics (Hameed et al., 1995). The 6-month peak in the CO2 spectrum (and the next harmonic at 4 months) may result from insolation-modulated changes in terrestrial photosynthesis.

However, in seeking to establish a range of working hypotheses, it is also plausible to conjecture a priori that annual $\mathrm{CO} 2$ forcing from terrestrial photosynthesis is predominantly sinusoidal in nature. Such forcing could stem from the yearly cycle of extratropical insolation that drives photosynthetic extraction of $\mathrm{CO} 2$ in the northern boreal and temperate forests and the rainforests of Southeast Asia. In this case, a distinct forcing mechanism with a 6 month period may account for the corresponding peak in the CO2 spectrum.

A possible explanation for a 6 month modulation of an annual sinusoid is a link to cyclic marine phytoplankton blooms. This conjecture is supported by spectral analysis of Nimbus-7 Coastal Zone Color Scanner (CZCS) monthly chlorophyll climatology data (Feldman et al., 1998). To compute a spectrum, the chlorophyll data were integrated over the northern oceans 
for each month of the climatology data to produce an average 12 month time series for the Northern Hemisphere. The spectrum shows significant peaks at periods of 6 and 12 months (Table I). The 6 month chlorophyll cycle again represents a deviation from an annual sinusoid, and probably has more direct links to the insolation cycle than do terrestrial systems. This curve has local maxima at 25-26 March and 23-24 September. If these cycles affect atmospheric $\mathrm{CO} 2$, the local chlorophyll maxima would correspond to the local minima in the isolated 6 month contribution to the CO2 curve. These CO2 minima occur at 24-25 August and 24 February, a lag of 152 days between local maxima of oceanic primary production and corresponding local minima of atmospheric $\mathrm{CO} 2$ concentration. The yearly marine chlorophyll cycle may also be convolved with the terrestrial signal, modifying the apparent hysteresis in annual atmospheric response. [Table 1] [Figure 4]

Using an adjustable window wavelet analysis, variations through time of the nominal periods can be discerned (Figure 4). The wavelet analysis provides an instantaneous estimate of the frequency content of the signal, as opposed to an average content over the sampled domain (as shown in Figure 2(a)-(d)). Ochadlick et al. (1993) discuss the numerical techniques. The ridgelines (bold lines) correspond to major peaks and valleys in the spectrum. Noticeable variation in the 1 year ridge occurs in the mid-1970s. It is likely that disrupted anthropogenic $\mathrm{CO} 2$ emissions resulting from the OPEC oil embargo affected the natural cycle. If this is true, then it raises the question of how much influence anthropogenic emissions have on the $\mathrm{CO}_{2}$ cycle in non-embargo years as well. The ridge at 6.2 years ( 0.16 cycles/year) displays greater variability than the yearly peak, probably owing to the non-linear nature of its origin. [Figure 5]

Figure 5 shows the three-peak spectral mean, which is the sum of the isolated contributions of the major peaks. This spectral mean fits the entire time series data set remarkably well, 
accounting for over $99 \%$ of the variation in the linear residual (in the $r^{2}$ sense). This result indicates that the complexity of subannual, annual and inter-annual atmospheric CO2 variability is not great.

\section{REFERENCES}

Conway, T.J. and Tans, P.P. 1998. Principal investigators for the NOAA/CMDL flask CO2 database. The data were accessed at http://cdiac.esd.ornl.gov/ftp/ndp005r3 in August, 1998.

Feldman, G., McClain, C. and Esaias, W. 1998. Principal investigators for the Nimbus-7

Coastal Zone Color Scanner (CZCS) monthly climatology chlorophyll data, accessed from NASA’s Goddard Space Flight Center at http://seawifs.gsfc.nasa.gov/SEAWIFS/IMAGES/CZCS_DATA.html in August, 1998.

Hameed, S., Currie, R.G. and LaGrone, H. 1995. 'Signals in atmospheric pressure variations from 2 to ca. 70 months: Part I. Simulations by two coupled ocean-atmosphere GCM's', Int. J. Climatol., 15, 853-871.

Ochadlick, A.R. Jr., Kritikos, H.N. and Giegengack, R.E. 1993. 'Variations in the period of the sunspot cycle', Geophys. Res. Lett., 20(14), 1471-1474.

Press, W.H., Teukolsky, S.A., Vetterling, W.T. and Flannery, B.P. 1992. Numerical Recipes In C: The Art of Scientific Computing, 2nd edn., Cambridge University Press, New York, 994 pp.

Sarmiento, J.L. 1993. 'Atmospheric CO2 stalled’, Nature, 365, 697-698. 


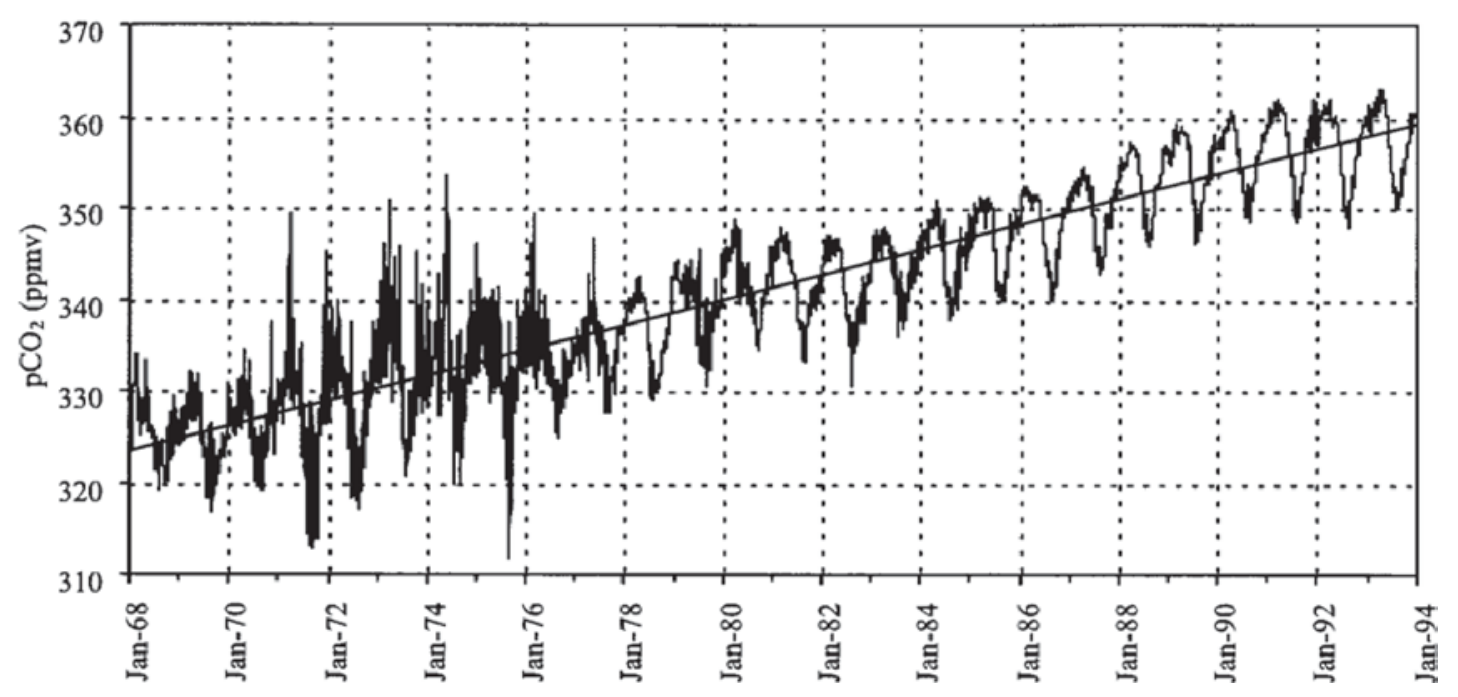

Figure 1. Daily average Northern Hemisphere atmospheric CO2 concentration computed from the records of 20 NOAA CMDL Flask database monitoring stations 


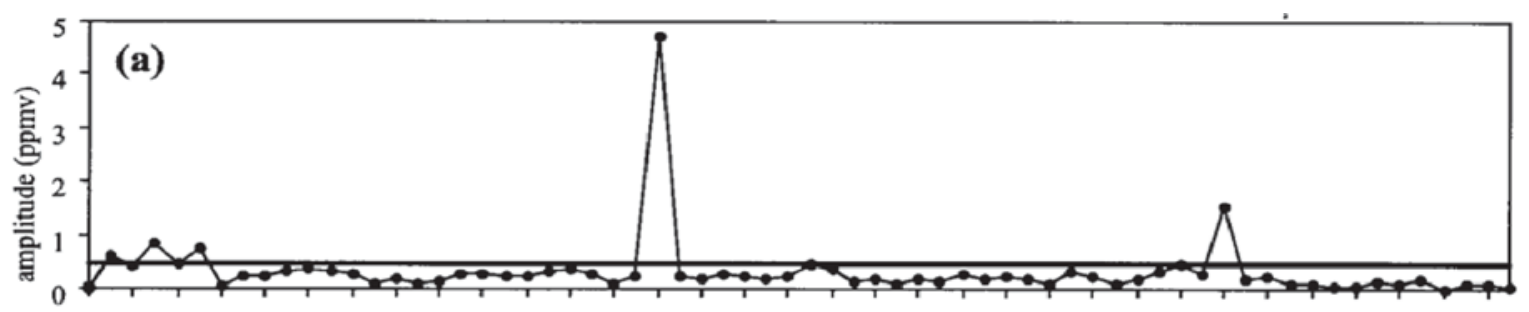

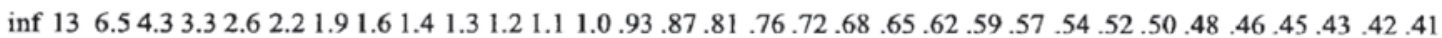

$\begin{array}{lllllllllllllllllllllllllllllllll}0 & 2 & 4 & 6 & 8 & 10 & 12 & 14 & 16 & 18 & 20 & 22 & 24 & 26 & 28 & 30 & 32 & 34 & 36 & 38 & 40 & 42 & 44 & 46 & 48 & 50 & 52 & 54 & 56 & 58 & 60 & 62 & 64\end{array}$ Period (years)

Wavenumber
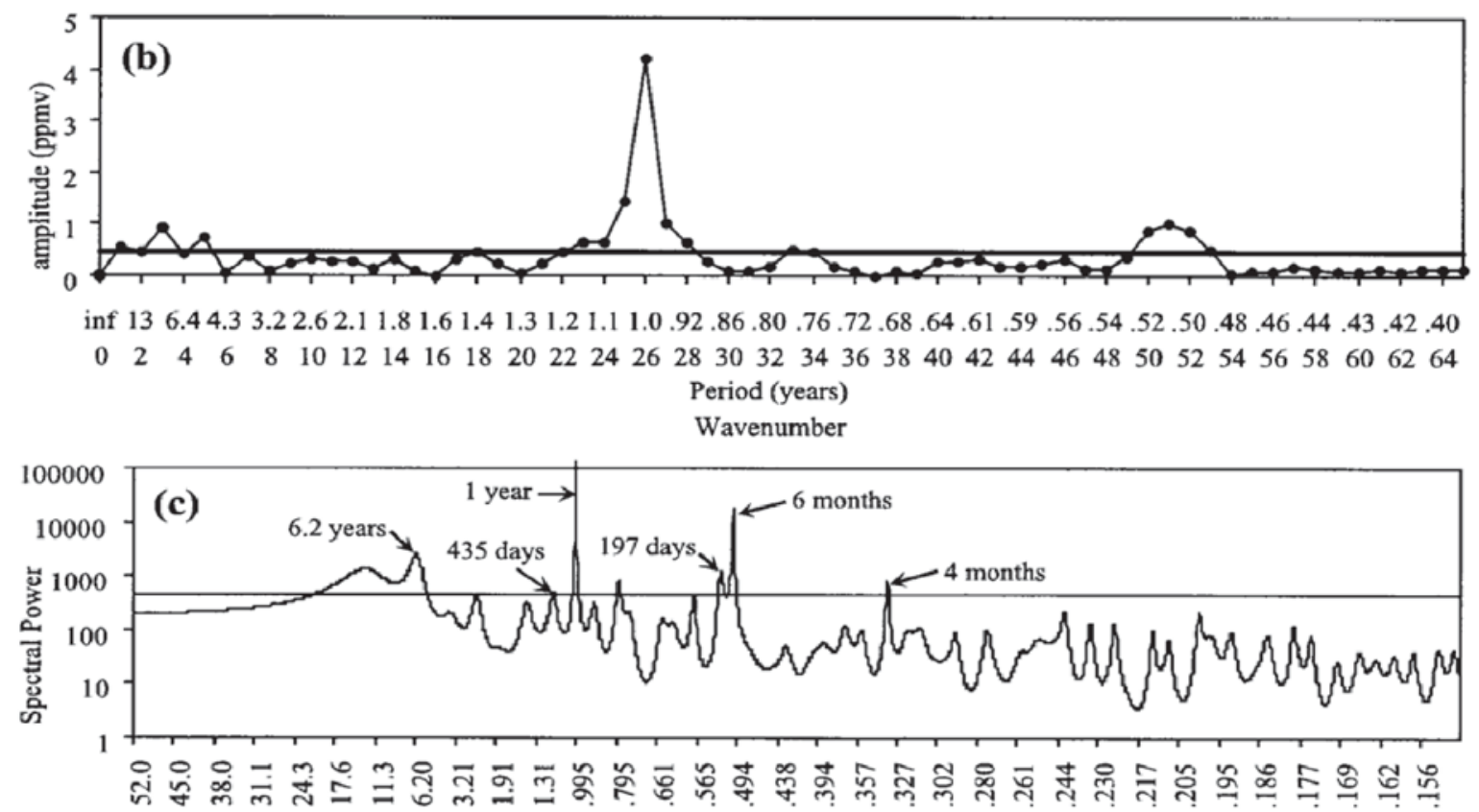

Period (years)

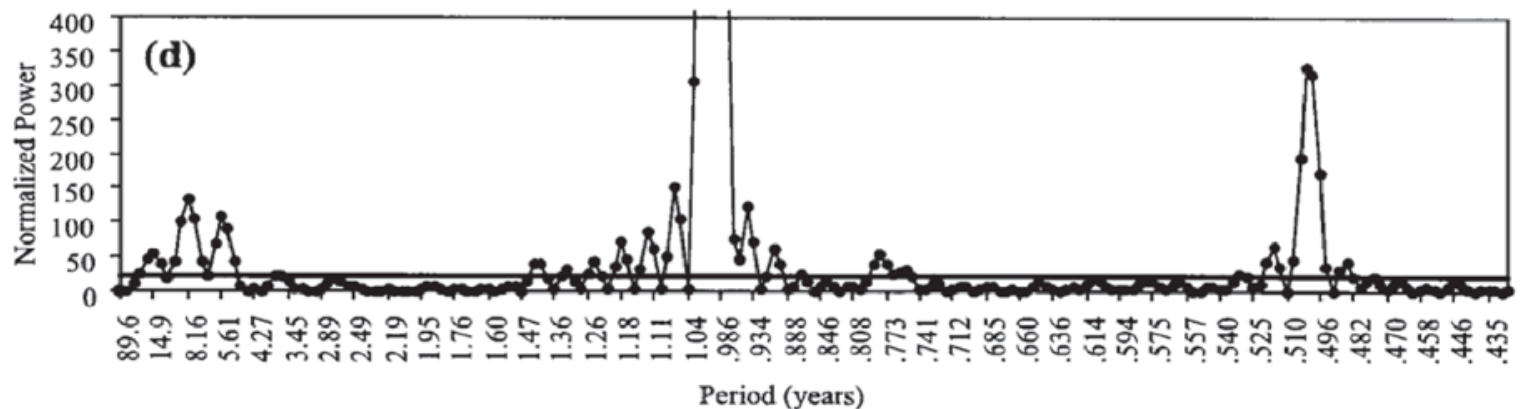

Figure 2. The spectrum of atmospheric CO2 concentration, as computed by: (a) DFT for the period 1 January 1968-31 December 1993; (b) DFT for the period 1 July 1968-31 December 1993; (c) MEM for the period 1 January 1968-31 December 1993; and (d) Lomb normalized periodogram for the period 1 January 1968-31 December 1993. The horizontal lines in each graph represent the 0.005 significance level of a test for distinctness from white noise 

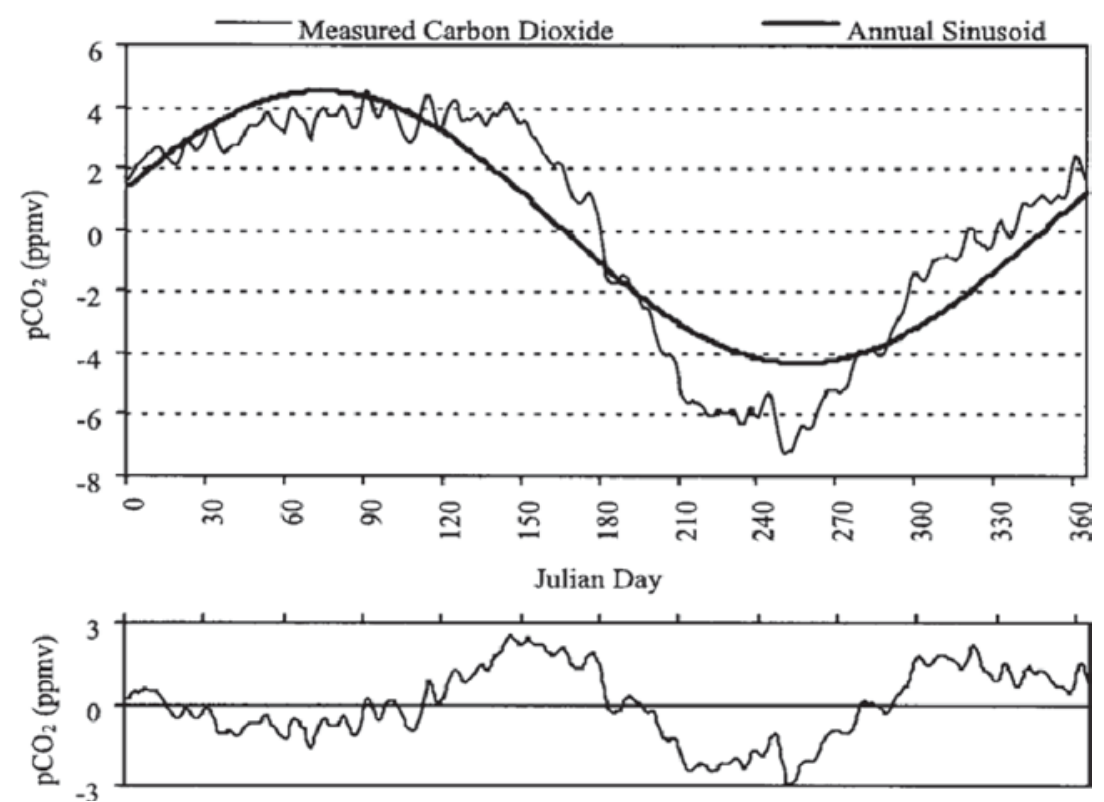

Figure 3. Isolated yearly sinusoid of CO2, computed by inverse DFT of wavenumber 26,

compared with the average annual signal for the period 1 January 1968-31 December 1993 (lower graph shows residual)

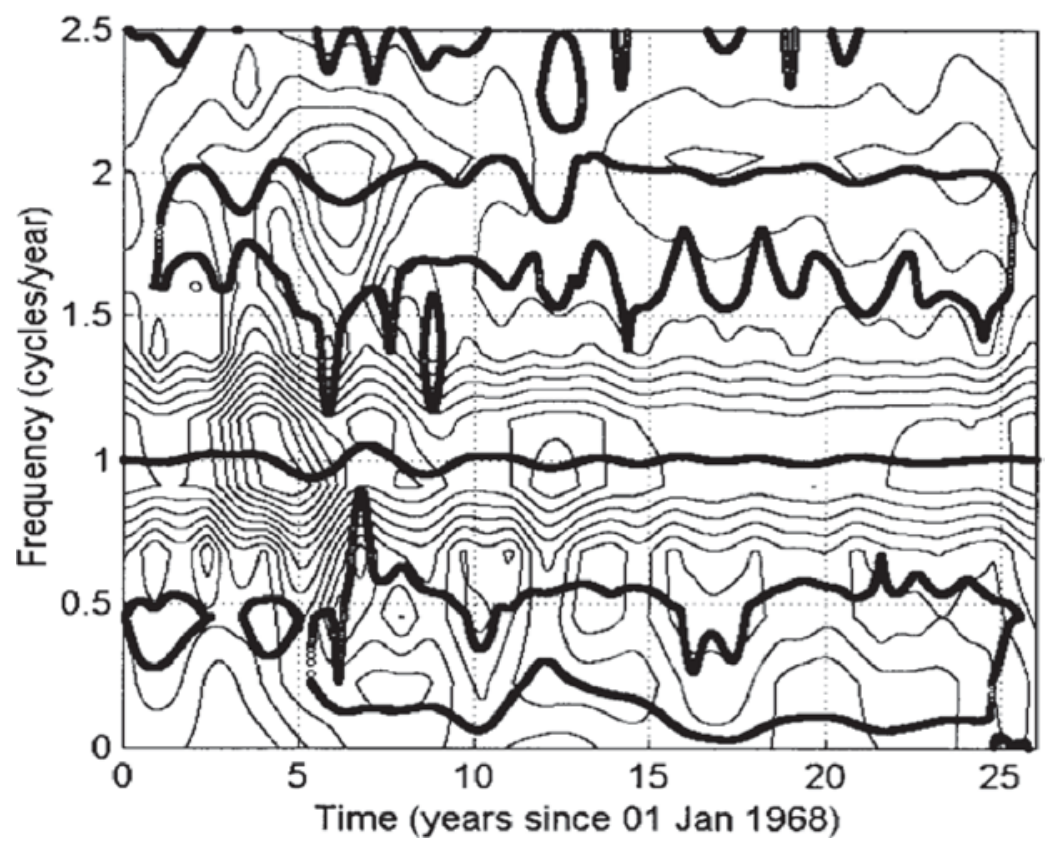

Figure 4. Results of adjustable window wavelet analysis, showing instantaneous estimates of frequency content at each point in time over the period 1 January 1968-31 December 1993. Bold lines represent ridges in the contour plot 

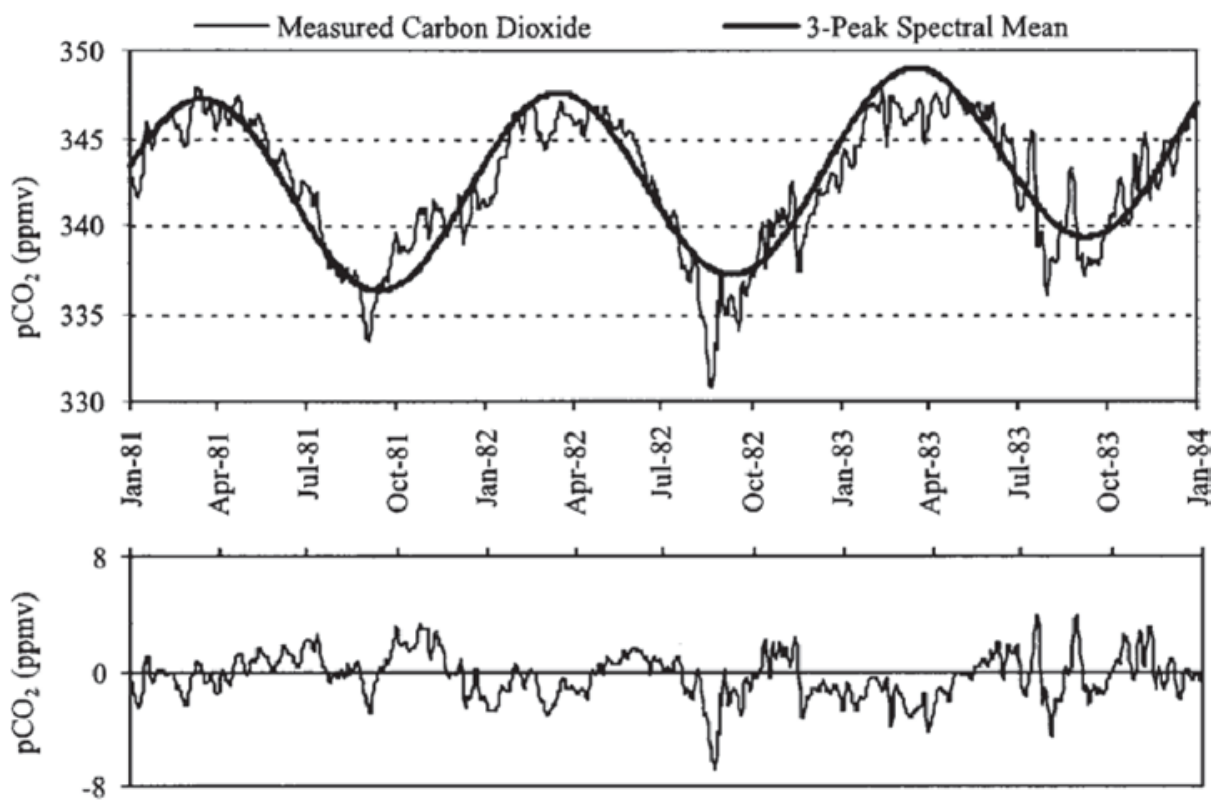

Figure 5. The spectral mean computed by inverse DFT of wavenumbers 4, 5 (the 6.2 year peak), 26 (the yearly peak) and 52 (the 6 month peak), as compared to measured values of atmospheric CO2 concentration (lower graph shows residual)

\begin{tabular}{|c|c|c|c|c|c|c|}
\hline \multicolumn{2}{|l|}{ Spectral peaks } & \multicolumn{2}{|l|}{ Atmospheric $\mathrm{CO}_{2}$} & \multicolumn{2}{|l|}{ CZCS chlorophyll } & \\
\hline Wavenumber & $\begin{array}{l}\text { Period } \\
\text { (years) }\end{array}$ & $\begin{array}{l}\text { Amplitude } \\
\text { (ppm V) }\end{array}$ & $\begin{array}{l}\text { Phase angle } \\
\left({ }^{\circ}\right)\end{array}$ & $\begin{array}{l}\text { Amplitude } \\
\text { (units) }\end{array}$ & $\begin{array}{l}\text { Phase angle } \\
\left({ }^{\circ}\right)\end{array}$ & \\
\hline \multirow[t]{4}{*}{$\begin{array}{l}26 \\
52\end{array}$} & $\begin{array}{l}1.00 \\
0.50\end{array}$ & $\begin{array}{l}4.71 \\
1.57\end{array}$ & $\begin{array}{r}72.0 \\
-74.0\end{array}$ & $\begin{array}{r}1301.1 \\
340.9\end{array}$ & $\begin{array}{r}-138.4 \\
165.0\end{array}$ & \\
\hline & & $\begin{array}{l}\text { Max Julian Day } \\
\text { date }\end{array}$ & $\begin{array}{l}\text { Min Julian Day } \\
\text { date }\end{array}$ & $\begin{array}{l}\text { Max Julian Day } \\
\text { date }\end{array}$ & $\begin{array}{l}\text { Min Julian Day } \\
\text { date }\end{array}$ & Lag \\
\hline & 1-year & $\begin{array}{l}74 \\
14-15 \text { March }\end{array}$ & $\begin{array}{l}256 \\
12-13 \text { September }\end{array}$ & $\begin{array}{l}225 \\
12-13 \text { August }\end{array}$ & $\begin{array}{l}43 \\
12 \text { February }\end{array}$ & 31 \\
\hline & 6-month & $\begin{array}{l}146 \\
25-26 \text { May } \\
328 \\
12-13 \text { December }\end{array}$ & $\begin{array}{l}55 \\
24 \text { February } \\
237 \\
24-25 \text { August }\end{array}$ & $\begin{array}{l}85 \\
25-26 \text { March } \\
267 \\
23-24 \text { September }\end{array}$ & $\begin{array}{l}176 \\
24-25 \text { June } \\
358 \\
23-24 \text { December }\end{array}$ & 152 \\
\hline
\end{tabular}

Table I. Summary of 1-year and 6-month spectral peaks for Northern Hemisphere atmospheric CO2 concentration and CZCS chlorophyll climatology data 

